\title{
Diffuse hydrological mass transport through catchments: scenario analysis of coupled physical and biogeochemical uncertainty effects
}

\author{
K. Persson, J. Jarsjö, and G. Destouni \\ Department of Physical Geography and Quaternary Geology, Stockholm University, 106 91, Stockholm, Sweden
}

Received: 8 April 2011 - Published in Hydrol. Earth Syst. Sci. Discuss.: 12 May 2011

Revised: 26 September 2011 - Accepted: 10 October 2011 - Published: 20 October 2011

\begin{abstract}
This paper quantifies and maps the effects of coupled physical and biogeochemical variability on diffuse hydrological mass transport through and from catchments. It further develops a scenario analysis approach and investigates its applicability for handling uncertainties about both physical and biogeochemical variability and their different possible cross-correlation. The approach enables identification of conservative assumptions, uncertainty ranges, as well as pollutant/nutrient release locations and situations for which further investigations are most needed in order to reduce the most important uncertainty effects. The present scenario results provide different statistical and geographic distributions of advective travel times for diffuse hydrological mass transport. The geographic mapping can be used to identify potential hotspot areas with large mass loading to downstream surface and coastal waters, as well as their opposite, potential lowest-impact areas within the catchment. Results for alternative travel time distributions show that neglect or underestimation of the physical advection variability, and in particular of those transport pathways with much shorter than average advective solute travel times, can lead to substantial underestimation of pollutant and nutrient loads to downstream surface and coastal waters. This is particularly true for relatively high catchment-characteristic product of average attenuation rate and average advective travel time, for which mass delivery would be near zero under assumed transport homogeneity but can be orders of magnitude higher for variable transport conditions. A scenario of high advection variability, with a significant fraction of relatively short travel times, combined with a relevant average
\end{abstract}

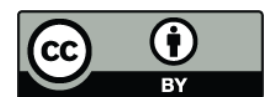

Correspondence to: K. Persson

(klas.persson@natgeo.su.se) biogeochemical mass attenuation rate, emerges consistently from the present results as a generally reasonable, conservative assumption for estimating maximum diffuse mass loading, when the prevailing physical and biogeochemical variability and cross-correlation are uncertain.

\section{Introduction}

Model estimations of diffuse hydrological mass transport are critical for biogeochemical cycle understanding, and successful and efficient environmental management. In many hydrological catchments with human activities, there are, apart from direct nutrient and pollutant discharges into surface waters, typically also diffuse sources at the land surface and below it, in soil, in mobile and immobile groundwater, and in sediments. Pollutants and excess nutrients that are transported from diffuse sources through the subsurface water system may yield considerable long-term loading to downstream surface and coastal waters (Carpenter et al., 1998; Baresel and Destouni, 2007; Darracq et al., 2008; Basu et al., 2010; Howden et al., 2011). Catchment-scale water quality modelling and prediction must account for this subsurface transport, even if the main focus is on surface water quality.

However, all models of solute transport through subsurface and surface water subsystems, and whole catchments are inevitably associated with uncertainties. Over the last decades, many successive publications have quantified different types of uncertainty and investigated their implications for the modelling and management of water pollution (e.g. Cvetkovic et al., 1992; Andricevic and Cvetkovic, 1996; Batchelor et al., 1998; Eggleston and Rojstaczer, 2000; Gren et al., 2000; Jarsjö et al., 2005). Key sources of uncertainty

Published by Copernicus Publications on behalf of the European Geosciences Union. 
in the quantification of waterborne mass transport along the hydrological source-pathway-recipient continuum include:

- the spatiotemporal configuration, variability and historic-to-future development and change of driving forces and conditions that determine source inputs, such as human activities, weather, climate and land cover/use conditions (Darracq et al., 2005; Hagemann and Jacob, 2007; Jacob et al., 2007; Edwards and Withers, 2008; Kyselý and Beranová, 2009; Bergknut et al., 2010)

- the transport pathways from the sources to the downstream observation points and receiving water environments, and the variability of water flow and mass transport velocities and travel times among and along these pathways (e.g. McGuire et al., 2005; Destouni et al., 2010; Beven, 2010; McDonnell et al., 2010)

- the variability of biogeochemical processes and their combination and cross-correlation with the physical mass transport along the different flow and transport pathways (e.g. Malmström et al., 2004, 2008; Darracq and Destouni, 2007; Cunningham and Fadel, 2007; Jardine, 2008)

- the errors of mass transport measurements implied by the chosen measurement methods and the coverage gaps between the chosen measurement points in time and space (e.g. Hannerz and Destouni, 2006; Beven, 2006; Jarsjö and Bayer-Raich, 2008; Destouni et al., 2008)

- the chosen model resolutions and possible neglect of potentially important contributing mass transport processes at different scales (e.g. Lindgren and Destouni, 2004; Refsgaard et al., 2006; Destouni et al., 2006; Ganoulis, 2009).

Among all these sources of hydrological mass transport uncertainty, only some can be accounted for by realistic probability assignment and statistical quantification. However, also the remaining, statistically unquantifiable uncertainties need to be accounted for in some way. One way to achieve this is to consider scenarios that capture and bound different possible system characteristics and developments.

Recent studies of hydrological pollutant transport have combined probabilistic and scenario uncertainty accounts, and discussed the needs and result implications of such combined approaches for rational guidance of management and abatement of water pollution (Baresel and Destouni, 2007; Persson and Destouni, 2009). These studies specifically addressed water pollution from local sources, with to large degree known locations and relatively limited spatial extents (commonly referred to as point sources), for which bounding scenarios of different possible mass transport statistics could be relatively well defined and quantified. However, for pollutant/nutrient/tracer transport from diffuse sources, with continuous or patch-wise spatial distributions over more or less the whole landscape within a catchment area, such statistics are considerably more difficult to obtain (e.g. McDonnell et al., 2010; Darracq et al., 2010a, b).

In this paper we use and develop a scenario analysis approach to quantify some relevant statistical uncertainty bounds for hydrological mass transport from spatially widespread sources at and below the land surface, through soil and groundwater, to surface and coastal waters within and downstream of a catchment. We formulate and combine different scenarios of variability in physical and biogeochemical mass transport processes at the catchment scale, and quantify and map the scenario-associated transport and delivery of, for instance, tracer, pollutant or excess nutrient mass, from a diffuse source over the entire land area of a catchment to downstream surface or coastal water recipients. We further assess the possible convergence, as well as the divergence and uncertainty among the different scenario results. The hydrologically well-characterised Forsmark catchment in Sweden (e.g. Johansson et al., 2005; SKB, 2008; Werner et al., 2007; Jarsjö et al., 2008) is used as a specific case study example.

Previous calculations of travel time distributions in the Forsmark catchment example have only considered a scenario of essentially constant $K$, prevailing along relatively high-conductive, preferential transport pathways through the catchment (Darracq et al., 2010a, b; Destouni et al., 2010). These calculations are here extended for a second, quite opposite flow and transport scenario, considering large spatial variability in the transport-encountered $K$. This scenario represents a transport situation, where the flow and transport pathways go through and encounter the full $K$ variability that prevails within a catchment, representing a realistic upper bound for the transport-encountered $K$ variability. The difference between the hydrological mass transport results for the constant and variable $K$ scenarios indicates then the importance of uncertainty about the prevailing $K$ heterogeneity in the catchment.

In addition to and combined with the different scenarios of physical $K$ heterogeneity and resulting advective travel time distributions, we consider here also different scenarios concerning the variability and cross-correlation with $K$ of the biogeochemical rate of pollutant/nutrient mass attenuation (decay or immobilisation by physical, chemical or biological processes) occurring along the mass transport pathways. Natural attenuation depends on subsurface characteristics, such as water flow velocity and mineralogy, which are also directly or indirectly related to hydraulic conductivity (Cunningham and Fadel, 2007; Jardine, 2008). Regarding bacterial degradation of organic contaminants, for instance, the subsurface permeability affects the availability of ratelimiting electron acceptors and donors, as well as the bacterial transport and community structure. Microbial processes 
Scenario 1:
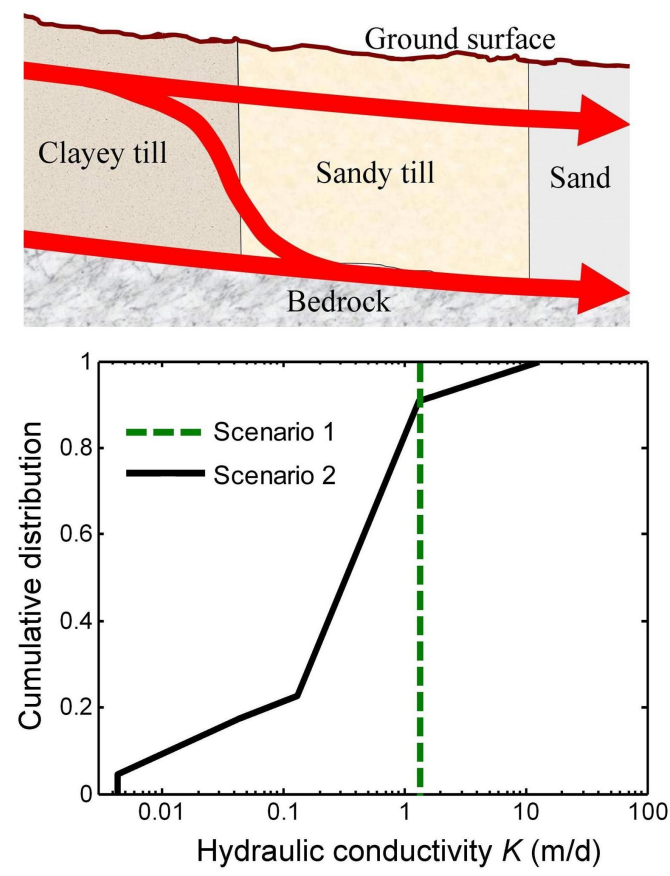

Scenario 2:

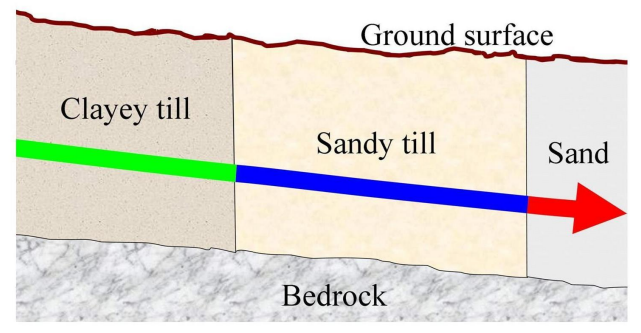

Spatial distribution of transportencountered $K$ in scenario 2:

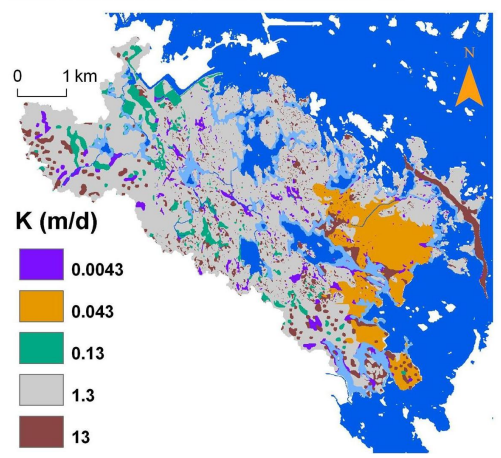

Fig. 1. Two scenarios of variability in saturated hydraulic conductivity, $K$, as encountered by the main flow and transport pathways (up) and their resulting cumulative $K$ distribution (down left) in the Forsmark catchment (map, down right). Different arrow colours represent different transport velocities. Scenario 1 (constant $K$ ) represents transport that occurs predominantly in high-conductivity aquifer zones, such as near the soil surface, at the soil-bedrock interface, and/or other inter-connected preferential flow paths. Scenario 2 (spatially variable $K$ ) represents transport through soil and aquifer zones where $K$ varies spatially according to the available information of soil cover and average permeability of each soil type.

can in turn also influence the permeability (Chapell, 2000). However, although there may clearly be a relation between attenuation and permeability, it is highly uncertain how and how strongly attenuation rates are correlated with $K$. Not even the sign of correlation can be determined a priori. The scientific literature contains empirical evidence and theoretical arguments for both negative and positive correlation (Cvetkovic and Shapiro, 1990; Destouni and Cvetkovic, 1991; Cozzarelli et al., 1999; Cunningham and Fadel, 2007; Jardine, 2008). An objective of the present study, along with the development of the scenario analysis approach, is therefore to investigate how, and how much hydrological solute mass transport through and from a catchment is affected by the complexity and uncertainty associated with the variability and possible cross-correlation of physical mass transport and biogeochemical mass attenuation.

\section{Materials and methods}

\subsection{The Forsmark catchment example}

Forsmark is a sparsely populated, $29.5 \mathrm{~km}^{2}$ catchment of a Baltic Sea coastal stretch, located about $100 \mathrm{~km}$ north of Stockholm, Sweden. The prevailing hydrological conditions in this catchment have been extensively investigated using measured and modelled geographical and hydrological data available at $10 \mathrm{~m}$ resolution (e.g. Johansson et al., 2005; Werner et al., 2007; Jarsjö et al., 2008).

The terrain in Forsmark is mildly undulating. Elevations range from 0 to $50 \mathrm{~m}$ above sea level (Brydsten and Strömgren, 2004). Quaternary deposits, predominantly till, cover the gneiss and granite bedrock in most of the area. The depth to the groundwater table is mostly less than $1 \mathrm{~m}$, and there is a strong correlation between small-scale topography and groundwater level. The undulating landscape appears to generate various small recharge areas of local groundwater flow systems (Werner et al., 2007). The long-term mean annual precipitation is around $560 \mathrm{~mm}$, of which about 25$30 \%$ falls as snow (Johansson and Öhman, 2008). Infiltration excess overland flow may occur, but only over short distances (SKB, 2008).

The landscape is characterised by forest, some small agricultural areas and a large number of lakes and wetlands. None of the lakes and wetlands is larger than $1 \mathrm{~km}^{2}$, many are smaller than a hectare, but altogether they constitute $19 \%$ of the total catchment area. Some of these lakes and wetlands are connected to each other and to the Baltic Sea by small streams. Others do not have any outlet and thus no surface 
water connection to the sea. About $10 \%$ of the area drains to stretches of the coast with no surface water outlet. Measurements of stream discharge are available from four gauging stations, but the time series are too short to provide reliable information about the spatial variation of runoff in the area (Johansson and Öhman, 2008).

\subsection{Quantification of advective solute travel times for physical heterogeneity scenarios}

We quantified groundwater travel times in the Forsmark catchment for two different, quite opposite scenarios of how the saturated hydraulic conductivity $K$ may vary among and along the different pathways of diffuse solute transport in this example catchment area. In Fig. 1 the scenarios are schematically illustrated, and their respective $K$ distributions are shown. In scenario 1 the transport-encountered $K$ is essentially constant, representing transport that largely evades low- $K$ zones and follows primarily preferential pathways through relatively high- $K$ zones. The constant $K$ value is then set to $1.3 \mathrm{~m} \mathrm{~d}^{-1}$, which was the uniform mean value suggested by Johansson et al. (2005) for the upper soil layer and for the soil - bedrock interface of Forsmark, based on field permeability testing and generic data. The soil - bedrock interface in this catchment is typically located at a depth of less than $5 \mathrm{~m}$ (Johansson, 2008). In scenario 2, the transportencountered $K$ varies both among and along the transport pathways through the catchment, in accordance with available data on the geographical distribution of different soil types over the catchment (Jarsjö et al., 2008) and site-specific and generic data of typical $K$ values for the different soil types (Johansson, 2008). In this scenario, the geometric mean value of $K$ is $0.71 \mathrm{md}^{-1}$, and the standard deviation of $\ln K$ is 1.8 .

The two scenarios 1 and 2 have thus very different $K$ distributions (Fig. 1), which can be expected to bound many alternative representations of $K$ variability in a catchment. Stochastic $K$ fluctuations around the mean local $K$ values (constant in scenario 1 and variable in scenario 2 ) are not included in the present scenario analysis, for illustrative simplicity and because such fluctuations were found to have a relatively minor impact on the catchment-scale travel time distribution. Persson and Destouni (2009) have also previously investigated the effects of such stochastic fluctuations for transport from point sources in a scenario 1-situation, for which the relative importance of these fluctuations is the greatest.

For the present two scenarios we used the same methodology as described by Darracq et al. (2010a, b) and Destouni et al. (2010) to quantify the distributions of advective solute travel times from a uniform source input over the whole land surface of the Forsmark catchment to the nearest inland or coastal surface water. Specifically, we used high-resolution $(10 \times 10 \mathrm{~m})$ elevation data to generate raster maps of ground slope and local flow direction (for simplicity, only a single flow direction was considered for each model cell). From these maps, we calculated advective solute travel times from each model cell through the groundwater to the nearest surface water. The total advective solute travel time $\tau$ from each model cell location $\underline{a}$, along the topographically derived flow and transport pathway, to the nearest downstream surface water at distance $x_{\mathrm{CP}}$, was then calculated from the horizontal cell-to-cell flow path lengths $\Delta x_{i}$ of $\mathrm{N}$ cells from $\underline{a}$ to $x_{\mathrm{CP}}$ (i.e. $\left.x_{\mathrm{CP}}=\sum_{i=1}^{N} \Delta x_{i}\right)$ and the estimated local mean advective transport velocities $v_{i}$ along the transport pathway as

$\tau=\sum_{i=1}^{N} \Delta \tau_{i}$, with $\Delta \tau_{i}=\Delta x_{i} / v_{i}$ and $v_{i}=\left[\left(K_{i} \cdot I_{i}\right) / n_{i}\right]$

where $I_{i}$ is the local hydraulic gradient and $n_{i}$ is the local effective porosity. The statistical distribution, and from that also the mean and standard deviation of $\tau$, was obtained by repeating this calculation of the flow paths to $x_{\mathrm{CP}}$ and the path-specific $\tau$ for all input points $\underline{a}$ over the entire catchment surface.

For both scenarios, the effective porosity was set to be $n=0.05$, as reported by Johansson (2008). The hydraulic gradient $I$ was set equal to the arithmetic average of the ground slope in all model cells within each one of the subcatchments of a total of 8783 outlets to the surface water network or the sea. Darracq et al. (2010a) have previously investigated the effect of alternative hydraulic gradient scenarios for the Forsmark catchment, and the two resulting travel distributions from the present two $K$ scenarios (shown and discussed further in the Results section below) bound the different travel time distributions resulting from their different $I$ scenarios.

\subsection{Quantification of mass delivery for physical- biogeochemical heterogeneity scenarios}

Based on the estimated advective travel time distributions for the two different $K$ variability scenarios, we further quantified the total cumulative mass delivery to surface water from all possible pollutant input locations over the whole land surface area in the Forsmark catchment. For an attenuation scenario of constant first-order mass attenuation rate $\lambda$, we quantified the delivered mass fraction $\alpha$ from each model cell at location $\underline{a}$ to the nearest surface water at $x_{\mathrm{CP}}$ as

$\alpha=\exp (-\lambda \tau)$

where $\tau$ is the advective travel time along the pathway from $\underline{a}$ to $x_{\mathrm{CP}}$, calculated as described above in Eq. (1).

For the $K$ variability scenario 2 , we also quantified the advective travel time-related mass delivery $\alpha$ for three different scenarios of variability in local attenuation rate $\lambda$ and its cross-correlation with local $K$ : 


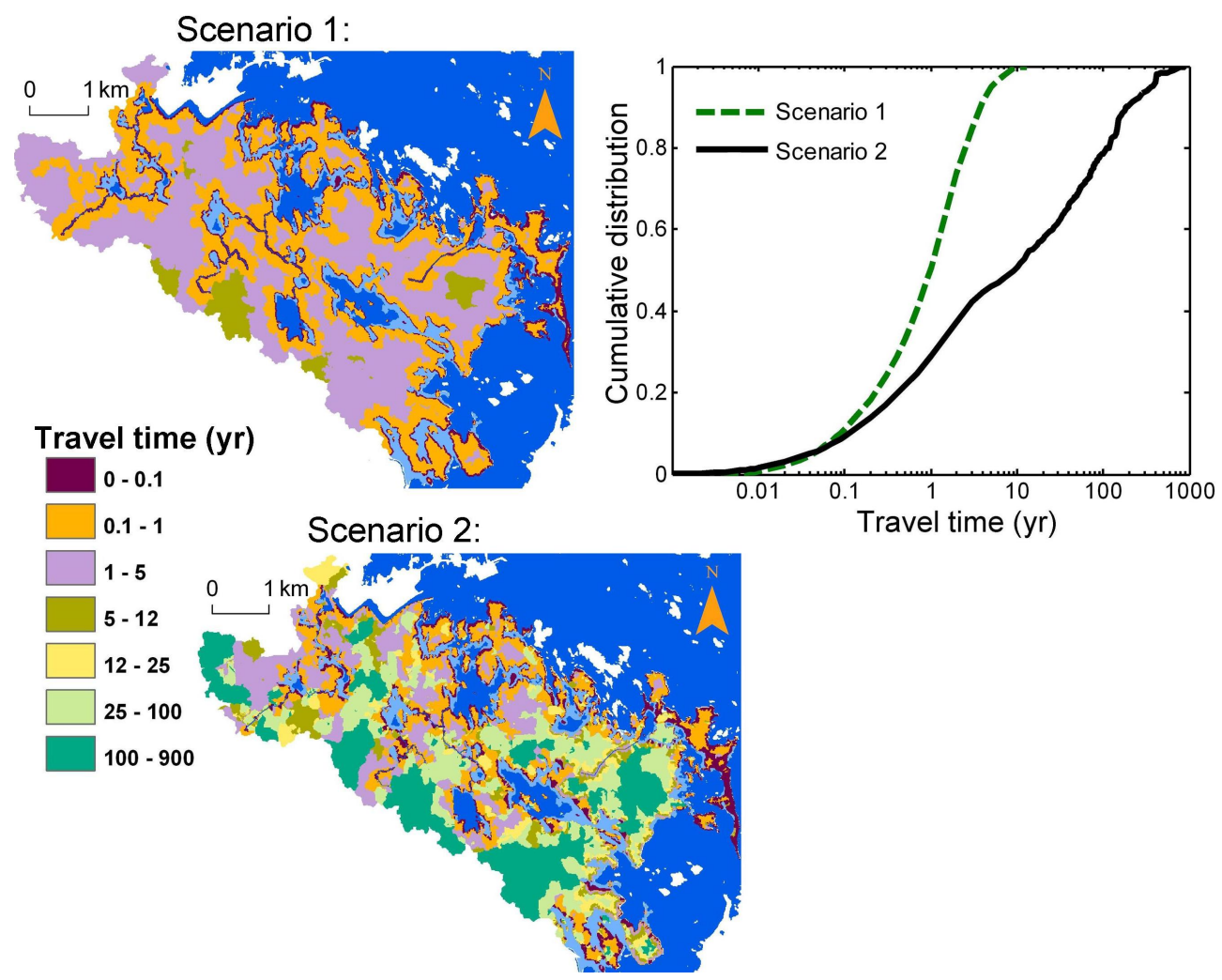

Fig. 2. The maps show advective travel times from different input locations in the Forsmark catchment to nearest surface water (inland or coastal) for the two considered $K$ variability scenarios. The graph shows the resulting cumulative distributions of travel time to surface water from all upstream input locations (model cells).

(i) $\lambda$ has perfect positive correlation with $K$ and is quantified as

$$
\lambda=\lambda_{\mathrm{g}} \cdot K / K_{\mathrm{g}}
$$

(ii) $\lambda$ has perfect negative correlation with $K$ and is quantified as

$$
\lambda=\lambda_{\mathrm{g}} \cdot\left(K / K_{\mathrm{g}}\right)^{-1}
$$

(iii) $\lambda$ is an independent, lognormally distributed random variable with $\log$ variance quantified from that of $K$ as

$$
V[\ln \lambda]=V[\ln K]
$$

where $\lambda_{\mathrm{g}}$ and $K_{\mathrm{g}}$ in Eqs. (3-4) are the geometric mean values of $\lambda$ and $K$ over the catchment, respectively.

For the different $\lambda$ variability scenarios, the local mass delivery $\alpha_{i}$ from each cell to the first downstream cell was calculated as

$\alpha_{i}=\exp \left(-\lambda_{i} \Delta \tau_{i}\right)$

and the total $\alpha$ along a transport pathway of $N$ cells from $\underline{a}$ to $x_{\mathrm{CP}}$ as

$\alpha=\prod_{i=1}^{N} \alpha_{i}$

\section{Results and discussion}

\subsection{Travel time distributions}

Figure 2 shows the maps and cumulative distributions of the advective solute travel times from every $10 \times 10 \mathrm{~m}$ model cell in the Forsmark catchment area to the nearest inland or coastal surface water for the two $K$ variability scenarios (Fig. 1). Travel time statistics for the two scenarios are also summarised in Table 1. The distributions of advective solute travel times are very different for the two scenarios 1 and 2 (Fig. 2). Scenario 2 results in the largest spreading of estimated travel times out of all the different travel time distribution scenarios reported by Darracq et al. $(2010 \mathrm{a}, \mathrm{b})$ for the Forsmark catchment, as well as for another investigated, nearby but much larger catchment in Sweden (the Norrström drainage basin. Those previously reported travel time distributions were calculated for different assumptions of hydraulic gradient variability and of the flow and transport interactions between shallow and deep groundwater along the subsurface pathways to the surface and coastal waters.

The travel time distribution for scenario 1 with constant $K$ shows the combined travel time spreading effect of the variability in transport pathway lengths and hydraulic gradients 
Table 1. Statistics of advective solute travel time $\tau$ to nearest surface water for the two $K$ variability scenarios in Fig. 1 .

\begin{tabular}{lllll}
\hline & $\begin{array}{l}\text { Geometric } \\
\text { mean } \tau(\mathrm{yr})\end{array}$ & $\begin{array}{l}\text { Standard de- } \\
\text { viation of } \ln \tau\end{array}$ & $\begin{array}{l}\text { Arithmetic } \\
\text { mean } \tau(\mathrm{yr})\end{array}$ & $\begin{array}{l}\text { Coefficient of } \\
\text { variation of } \tau\end{array}$ \\
\hline Scenario 1 & 0.73 & 1.5 & 1.5 & 1.1 \\
Scenario 2 & 6.1 & 2.9 & 66 & 1.9 \\
\hline
\end{tabular}

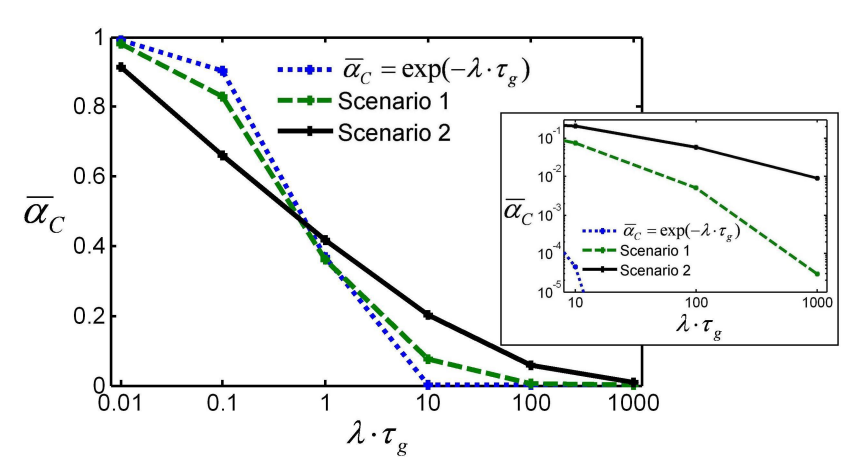

Fig. 3. Total (catchment-average) mass delivery fraction to nearest surface water from all upstream input locations in the Forsmark catchment, $\bar{\alpha}_{\mathrm{C}}$, under the assumption of constant $\lambda$ for the two considered scenarios regarding $K$ variability, and for a calculation approach where the travel time variability around the geometric mean $\tau_{\mathrm{g}}$ is neglected so that $\bar{\alpha}_{\mathrm{C}}=\exp \left(-\lambda \tau_{\mathrm{g}}\right)$. The small inset graph shows in clearer axis log-scale the $\bar{\alpha}_{\mathrm{C}}$ results for large characteristic attenuation products $\lambda \tau_{\mathrm{g}}$.

among the different transport pathways through the catchment. The travel time distribution for scenario 2 shows the added travel time spreading effect of the full $K$ variability across the catchment, where the flow and transport do not evade this variability by following relatively high-conductive preferential pathways as in scenario 1 .

\subsection{Mass delivery for physical heterogeneity scenarios}

Figure 3 shows, for the specific attenuation case of uniform first-order attenuation rate $\lambda$, the total, or catchmentaverage, mass delivery fraction, $\bar{\alpha}_{\mathrm{C}}$, to the nearest surface water from a uniform mass input over the entire land area in the Forsmark catchment, for a range of different catchmentcharacteristic products $\lambda \tau_{\mathrm{g}}$, where $\tau_{\mathrm{g}}$ is the geometric mean advective travel time to surface water in the catchment. Results are shown for the different travel time distributions of the $K$ variability scenarios 1 and 2 , and for comparison also for the common approach in lumped hydrological modelling to just use a single representative (mean) travel time for a whole (sub)catchment (see for instance also discussions about this approach and its effects in Destouni et al. (2010) and references therein). To represent this lumped approach, where the travel time distribution around $\tau_{\mathrm{g}}$ is neglected, the total mass delivery fraction to nearest surface water from the diffuse source input over the whole catchment is calculated as

$\bar{\alpha}_{\mathrm{C}}=\exp \left(-\lambda \tau_{\mathrm{g}}\right)$

Results are shown for normalised attenuation rate $\lambda \tau_{\mathrm{g}}$ in order to isolate and distinguish general effects of uncertainty about travel time variability around $\tau_{\mathrm{g}}$, and to facilitate understanding and comparison of these effects in different catchments with different characteristic $\tau_{\mathrm{g}}$. As a complement to this general quantification, Table 2 also shows how the normalised attenuation rate $\lambda \tau_{\mathrm{g}}$ will differ between different characteristic $\tau_{\mathrm{g}}$ scenarios for a given estimated mass attenuation rate $\lambda$ of a specific pollutant of interest.

In general, the catchment-average mass delivery $\bar{\alpha}_{\mathrm{C}}$ estimated with the lumped, single travel time approach in Equation 8 falls more rapidly toward zero as $\lambda \tau_{\mathrm{g}}$ increases than the mass delivery $\bar{\alpha}_{\mathrm{C}}$ obtained for all different $\tau$ in the catchment from Eq. (2) and the Equation set (6-7) in the variabilityaccounting scenarios 1 and 2 , respectively. For $\lambda \tau_{\mathrm{g}}$ in the order of 1 or greater, larger spreading of travel times around $\tau_{\mathrm{g}}$ increases the total mass delivery $\bar{\alpha}_{\mathrm{C}}$. Scenario 2 then yields the largest $\bar{\alpha}_{\mathrm{C}}$ because it has the largest fraction of transport pathways with advective travel times much shorter than $\tau_{\mathrm{g}}$, along which a significant mass fraction can reach the recipient, even for large characteristic attenuation product $\lambda \tau_{\mathrm{g}}$. For $\lambda \tau_{\mathrm{g}}$ smaller than 1 , by contrast, larger spreading of travel times around $\tau_{\mathrm{g}}$ decreases the mass delivery $\bar{\alpha}_{\mathrm{C}}$. Scenario 2 then results in the smallest $\bar{\alpha}_{\mathrm{C}}$ because it has the largest fraction of much longer travel times than $\tau_{\mathrm{g}}$, where some mass is attenuated even for small $\lambda \tau_{\mathrm{g}}$.

For comparison with the investigated $\lambda \tau_{\mathrm{g}}$ range in Fig. 3 , Table 2 shows examples of some typical orders of magnitude of attenuation rate $\lambda$ reported in the literature for different organic pollutants, metals and nutrients. Furthermore, Table 2 lists the associated order of magnitude of the catchmentcharacteristic product $\lambda \tau_{\mathrm{g}}$ in the two $K$ variability scenarios $1\left(\tau_{\mathrm{g}}=0.73 \mathrm{yr}\right)$ and $2\left(\tau_{\mathrm{g}}=6.1 \mathrm{yr}\right)$. The reported attenuation rates for most substances range over large intervals, because the attenuation processes depend on environmental conditions (such as water flow velocity, microbial activity, and the availability of oxygen and other electron acceptors or donors) that vary within and between sites. In addition, estimates of attenuation rates in the field are based on approximations and simplified assumptions that may introduce considerable 
Table 2. Examples of pollutants and nutrients with corresponding estimates of first-order attenuation rate $\lambda$ from reported field studies, and associated order of magnitude of the attenuation product $\lambda \tau_{\mathrm{g}}$ for scenarios $1-2$ in the Forsmark catchment area.

\begin{tabular}{|c|c|c|c|}
\hline \multirow[b]{2}{*}{$\begin{array}{l}\text { Example pollutants (for which given } \lambda \\
\text { is consistent with field observations of } \lambda \text { ) }\end{array}$} & \multirow[b]{2}{*}{$\begin{array}{l}\text { Attenuation rate } \\
\left(\mathrm{yr}^{-1}\right)\end{array}$} & \multicolumn{2}{|c|}{ Attenuation product } \\
\hline & & $\begin{array}{l}\text { Scenario } 1 \\
\tau_{\mathrm{g}}=0.73 \mathrm{yr}\end{array}$ & $\begin{array}{l}\text { Scenario } 2 \\
\tau_{\mathrm{g}}=6.1 \mathrm{yr}\end{array}$ \\
\hline 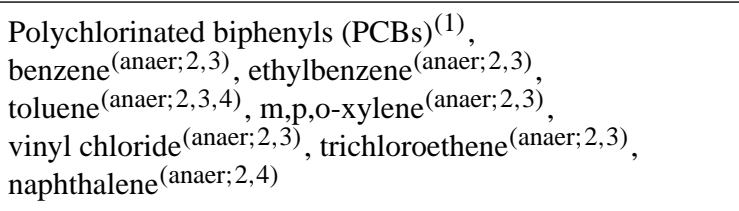 & $\leq 0.014$ & $\leq 0.01$ & $\leq 0.1$ \\
\hline 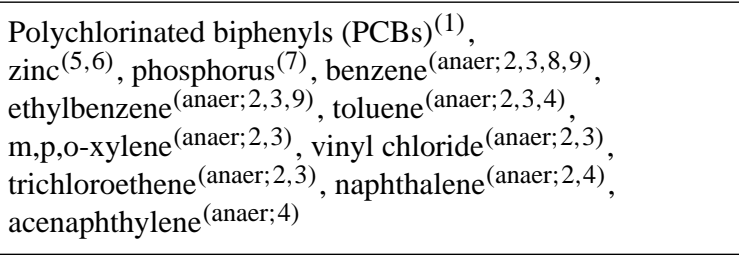 & 0.14 & 0.1 & 1 \\
\hline 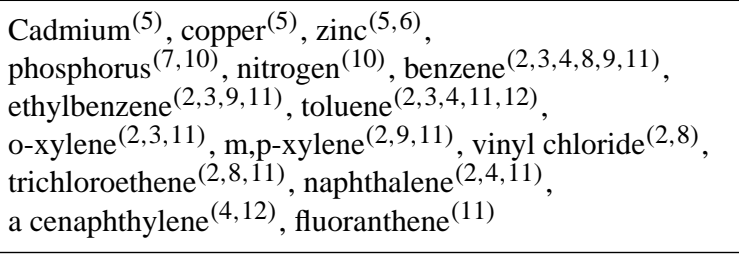 & 1.4 & 1 & 10 \\
\hline 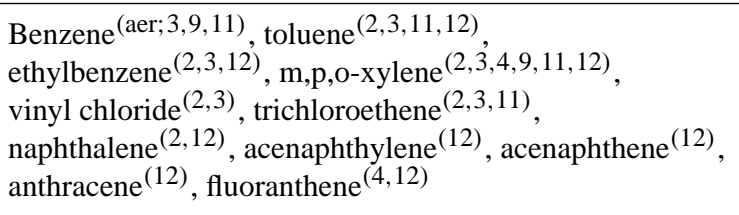 & 14 & 10 & 100 \\
\hline $\begin{array}{l}\text { Benzene }^{(\text {aer; } 3,12)}, \text { toluene }^{(\text {aer; } 3,11,12)} \\
\text { ethylbenzene } \\
\text { vinyl chloride }^{(\text {aer; } 3)}, \text { trichloroethene }^{(\text {aer; } 3,11)}\end{array}$ & 140 & 100 & 1000 \\
\hline Benzene $^{(\text {aer;3) }}$, toluene $^{(\text {aer;3,11)}}$, ethylbenzene $^{(\text {aer; 3) }}$ & $\geq 1400$ & $\geq 1000$ & $\geq 10000$ \\
\hline
\end{tabular}

(1) Sinkkonen and Paasivirta (2000), (2) Aronson and Howard (1997), ${ }^{(3)}$ Suarez and Rifai (1999), ${ }^{4)}$ Rogers et al. (2002), ${ }^{(5)}$ Baresel et al. (2006), ${ }^{(6)}$ Baresel and Destouni (2007), (7) Destouni et al. (2010), (8) Mulligan and Yong (2004), ${ }^{(9)}$ Essaid et al. (2003), ${ }^{(10)}$ Darracq et al. (2008) ${ }^{(11)}$ Aronson et al. (1999), ${ }^{12)}$ Bayer-Raich et al. (2006); (aer) Mainly relevant for aerobic conditions, ${ }^{(a n a e r)}$ Mainly relevant for anaerobic conditions.

errors (Bekins et al., 1998; Suarez and Rifai, 1999; Washington and Cameron, 2001; Mulligan and Yong, 2004). Nevertheless, Table 2 demonstrates that the investigated $\lambda \tau_{\mathrm{g}}$ range in this paper is relevant for a wide range of different environmental pollutants and characteristic catchment conditions; the latter because the investigated travel time pdfs bound a wide range of different possible catchment situations regarding advective transport and its associated uncertainties (see comparisons between different scenarios and catchment examples in Darracq et al., 2010a, b). For the quantification of the waterborne transport of some compounds of interest in a specific (sub)catchment, the range of relevant reported attenuation rates can be narrowed through a more detailed assessment of the prevailing environmental conditions in relation to the ones reported at the sites where attenuation rates of these compounds have been estimated in previous studies. Table 2 further shows that for scenario 2 the catchment-relevant $\lambda \tau_{\mathrm{g}}$ range for some substances under aerobic attenuation conditions may extend to even greater values than the maximum $\lambda \tau_{\mathrm{g}}=1000$ shown in Fig. 3. If the prevailing catchmentscale $\tau$ variability is neglected or underestimated (Fig. 3), high- $\lambda \tau_{\mathrm{g}}$ conditions and resulting underestimation of pollutant delivery $\bar{\alpha}_{\mathrm{C}}$ may be more likely to occur in the field for these and other substances than low- $\lambda \tau_{\mathrm{g}}$ conditions with $\bar{\alpha}_{\mathrm{C}}$ overestimation. 


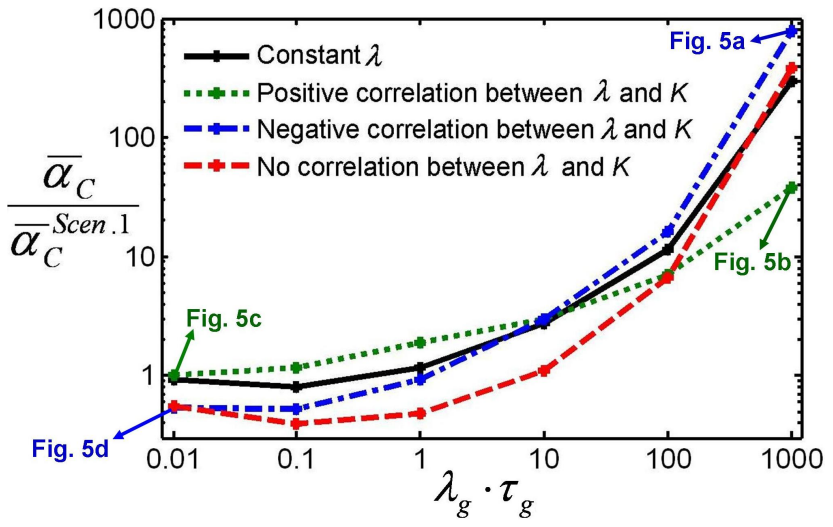

Fig. 4. Total (catchment-average) mass delivery fraction to nearest surface water from all upstream input locations in the Forsmark catchment, $\bar{\alpha}_{C}$. Mass delivery $\bar{\alpha}_{\mathrm{C}}$ results are shown for different assumptions regarding the correlation between $K$ and $\lambda$ in the $K$ variability scenario 2 , relative to $\bar{\alpha}_{\mathrm{C}}$ for the $K$ variability scenario 1 (in which both $K$ and $\lambda$ are constant). Corresponding maps of local mass delivery $\alpha$ to nearest surface water are shown in Fig. 5 for the four specific result points indicated in this figure.

\subsection{Mass delivery for physical-biogeochemical heterogeneity scenarios}

For the possibility that also $\lambda$ varies, along with $K$ and $\tau$, Fig. 4 shows for different cases of correlation between $\lambda$ and $K$, the resulting catchment-average $\bar{\alpha}_{\mathrm{C}}$ in scenario 2 , relative to that in scenario 1 , which has constant $K$ and $\lambda$, and smaller resulting $\tau$ variability (Fig. 2). For $\lambda_{\mathrm{g}} \tau_{\mathrm{g}}<10$, the variable $\lambda$ cases of negative or no $\lambda-K$ correlation yield pollutant mass delivery $\bar{\alpha}_{C}$ that is smaller than that of positive correlation or no $\lambda$ variability. The negative $\lambda-K$ correlation implies that the zones with smaller than average $K$ have larger than average attenuation rate $\lambda$, with both factors increasing pollutant attenuation relative to average conditions. In the case of no $\lambda-K$ correlation, where $\lambda$ in each model cell is an independent random variable, $\lambda$ is much greater than average along considerable parts of most transport pathways; this variability manifestation then results in more attenuated mass in total, and thereby smaller mass delivery $\bar{\alpha}_{\mathrm{C}}$, compared to the constant $\lambda$ variability case for a wide range of average $\lambda_{\mathrm{g}} \tau_{\mathrm{g}}$ conditions. For positive $\lambda-K$ correlation, the zones with larger than average $\lambda$ also have larger than average $K$, so that the $\lambda$ effect is to increase and the $K$ effect is to decrease pollutant attenuation; together these opposite effects may balance the resulting attenuation close to average $\lambda$ and $K$ conditions.

Figure 5 shows maps of the local mass delivery fraction $\alpha$ to the nearest surface water from all possible input locations in the Forsmark catchment. Results are shown for some different combinations (as indicated also in Fig. 4) of $\lambda_{\mathrm{g}} \tau_{\mathrm{g}}$ value and correlation between $K$ and $\lambda$. Comparison between the maps for lower $\lambda_{\mathrm{g}} \tau_{\mathrm{g}}$ values shown in Fig. $5 \mathrm{c}$ and $d$ specifically enables the identification of the main land areas within the catchment that are responsible for the massdelivery divergence between the different $\lambda$ variability and $K$ correlation cases. These are the green-coloured areas with mass delivery $<0.01 \%$ in the lower-right, negativecorrelation map, which are instead red-coloured with mass delivery $>50 \%$ in the lower-left, positive-correlation map. These are also more generally the potential lowest-impact areas in the catchment, i.e. those with the potential smallest relative mass delivery to surface water. The transport pathways from these areas to nearest surface/coastal water may be more or less forced to go through low-conductivity (smaller than average $K$ ) zones in possible alternative transport scenarios, which are bounded by the extreme scenarios 1 and 2; with the possible exception of the positive $\lambda$ $K$ correlation case, these transport pathways will then have larger mass attenuation than the other transport pathways in the catchment.

Relative to scenario 1 , in which $K$ is constant, all the $\lambda$ variability and correlation cases for scenario 2 yield smaller, or up to about the same, pollutant delivery $\bar{\alpha}_{\mathrm{C}}$ for $\lambda_{\mathrm{g}} \tau_{\mathrm{g}}<1$ (see Fig. 4). As $\lambda_{\mathrm{g}} \tau_{\mathrm{g}}$ increases, the effects of $\lambda$ and $K$ variability on $\bar{\alpha}_{\mathrm{C}}$ become opposite to those for low $\lambda_{\mathrm{g}} \tau_{\mathrm{g}}$. For larger $\lambda_{\mathrm{g}} \tau_{\mathrm{g}}$, more pollutant mass is of course attenuated on the average. Mass delivery to surface and coastal waters becomes insignificant from a growing part of the catchment, and an increasing fraction of the total mass delivery comes from areas with relatively short pathway lengths to nearest surface or coastal water and greater than average hydraulic gradient $I$ and conductivity $K$. The negative $\lambda-K$ correlation case yields the largest mass delivery from such high$K$ areas with particularly short travel times to the recipient. These areas then emerge as potential hotspots for pollutant loading from the catchment; these are the red-coloured areas, with mass delivery $>50 \%$ for $\lambda_{\mathrm{g}} \tau_{\mathrm{g}}=1000$ in the negative-correlation case, which are almost entirely greencoloured, with mass delivery $<1 \%$ in the positive correlation case (Fig. 5a). These potential hotspots are responsible for the much higher (up to factor 1000 for $\lambda_{\mathrm{g}} \tau_{\mathrm{g}}=1000$; see result point for map 5a indicated in Fig. 4) total mass load into surface/coastal waters for large $\lambda_{\mathrm{g}} \tau_{\mathrm{g}}$ in scenario 2 than in scenario 1 (and the even greater relative difference between mass load in scenario 2 and that for constant $\tau$ and $\lambda$, shown in Fig. 3). Even though not particularly high in relation to the total mass input (maximum $\bar{\alpha}_{\mathrm{C}}=0.023$ for $\lambda_{\mathrm{g}} \tau_{\mathrm{g}}=1000$; Fig. 5a), a factor 1000 greater pollutant load can shift environmental and health risk assessments, from no risk to large risk, for highly toxic pollutants with environmental limit values at or near detection level.

In general, across the whole $\lambda_{\mathrm{g}} \tau_{\mathrm{g}}$ range, the high $\tau$ variability scenario 2 with constant $\lambda$ yields $\bar{\alpha}_{C}$ close to the maximum- $\bar{\alpha}_{C}$ results associated with either the positive (for $\left.\lambda_{\mathrm{g}} \tau_{\mathrm{g}}<10\right)$ or the negative for $\lambda_{\mathrm{g}} \tau_{\mathrm{g}}>10 \lambda-K$ correlation cases (Fig. 4). A scenario of high physical $\tau$ variability, with a significant fraction of relatively short travel times, 

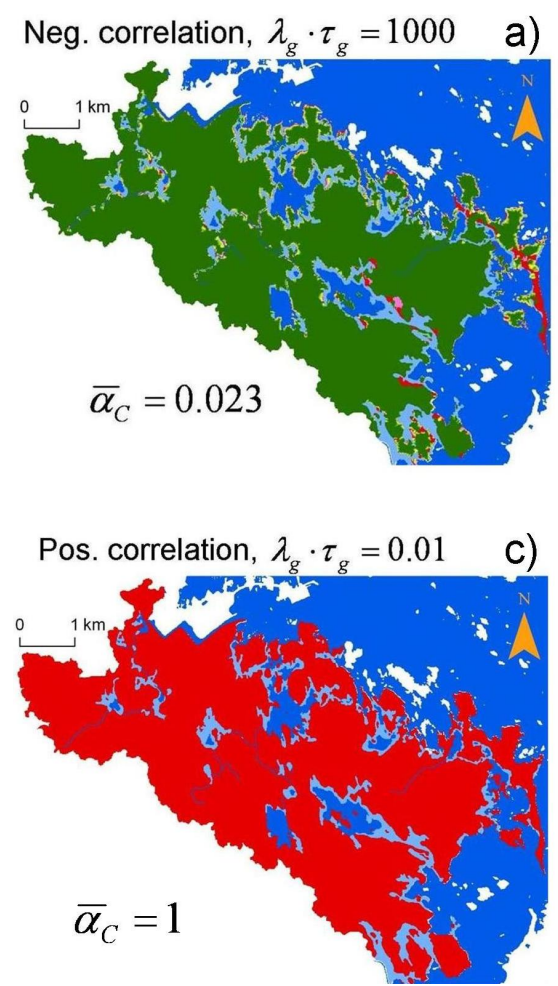
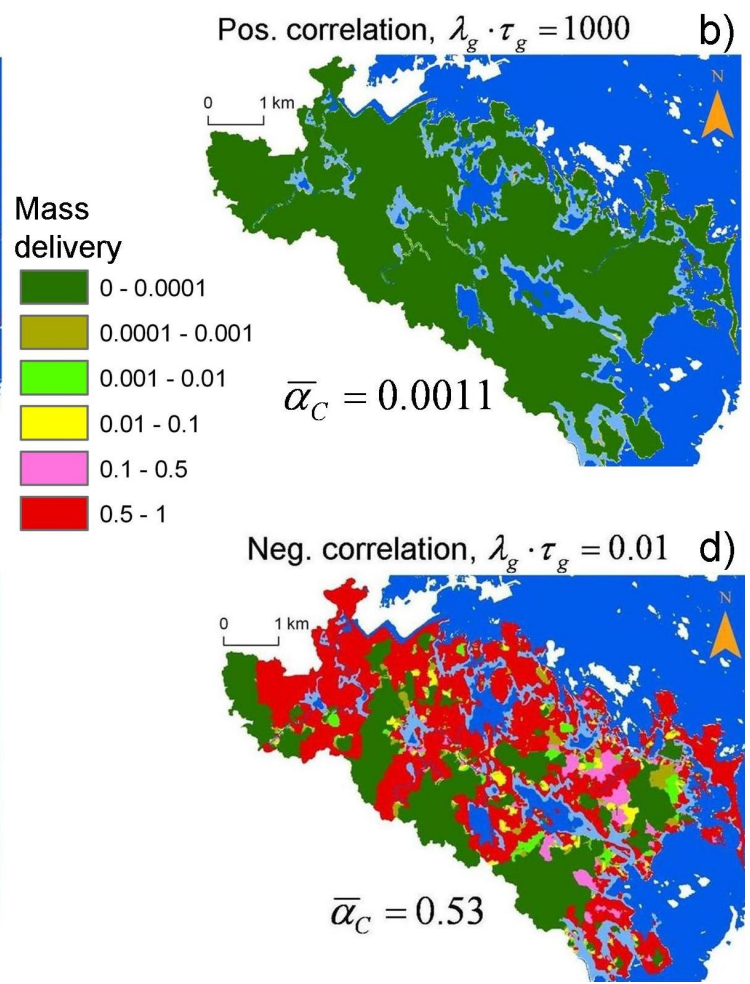

Fig. 5. Maps of local mass delivery fraction $\alpha$ to nearest surface water from different input locations in the Forsmark catchment. Results are shown for different combinations of $\lambda_{\mathrm{g}} \tau_{\mathrm{g}}$ value and correlation between $K$ and $\lambda$ in the $K$ variability scenario 2, as indicated in Fig. 4 .

combined with a relevant average $\lambda$ value can thus be considered as a reasonable conservative scenario assumption when field data and information are lacking for more precisely determining actual $K-\tau$ variability and $\lambda-K$ correlation. Furthermore, the advective travel time $\tau$ map of a high $\tau$ variability scenario may also be directly (i.e. without further attenuation calculations and mass delivery mapping for different $\lambda-K$ correlation cases) useful for at least an approximate identification of potential hotspot zones for large average $\lambda_{\mathrm{g}} \tau_{\mathrm{g}}$ (red in Fig. 5a) and low-impact zones for small average $\lambda_{\mathrm{g}} \tau_{\mathrm{g}}$ (green in Fig. 5d). In the present catchment example, these zones are indeed directly identifiable from the $\tau$ map for scenario 2: compare the areas with the shortest and the longest travel times in the lower map of Fig. 2 with the red hotspot areas in the Fig. 5a map and the green low-impact areas in the Fig. 5d map, respectively.

\section{Conclusions}

We have developed and shown the applicability of a scenario analysis approach to quantify and map the effects of uncertainty about physical and biogeochemical variability, cross-correlation and uncertainty on expected mass loading from diffuse sources. The approach is useful when field data and information is lacking for reliable determination of actual physical and biogeochemical variability and crosscorrelation conditions in a catchment. It enables identifica- tion of conservative assumptions, uncertainty ranges, as well as pollutant/nutrient input locations and situations for which further investigations are most needed in order to reduce the uncertainty.

The investigated variability scenarios have provided some relevant statistical distributions, bounding a range of different possible advective travel time statistics for diffuse hydrological mass transport from spatially widespread sources at and below the land surface, through soil and groundwater, to surface and coastal waters. Furthermore, the combined physical (advective) transport scenarios and mass attenuation cases in this study bound a wide range of different catchment conditions and types of pollutants and nutrients that may be accidentally, occasionally or continuously released from diffuse sources, as a result of current and/or historic human activities and remaining pollution legacies.

The results show that neglect or underestimation of the physical variability in subsurface hydraulic properties, and in particular of those transport pathways with much shorter than average advective solute travel times, can lead to substantial underestimation of pollutant and nutrient loading to downstream surface and coastal waters. This is particularly true for relatively high catchment-characteristic product $\left(\lambda_{\mathrm{g}} \tau_{\mathrm{g}}>10\right)$ of average attenuation rate and average advective travel time, for which mass delivery would be near zero under assumed transport homogeneity but can be orders of magnitude higher for variable transport conditions. 
The study results further show that a scenario of high physical advection variability, with a significant fraction of relatively short travel times (here scenario 2 ), combined with a relevant average biogeochemical attenuation rate, may be a generally reasonable, conservative assumption for estimating maximum diffuse mass loading when the prevailing physical and biogeochemical variability and cross-correlation are uncertain. A conservative travel time distribution can for instance be constructed by combining the shape of the statistical distribution of travel times obtained for a scenario of high physical advection variability around catchment-average advection conditions, with some estimated, relatively short mean advective travel time obtained for a transport scenario with dominant, relatively fast preferential pathways, as in the present scenario 1.

As done here for scenario 2, scenarios of large relative travel time spreading can consider the finest resolved available catchment data on topography and soil variability, which can be further translated into hydraulic conductivity and hydraulic gradient patterns, respectively. These patterns together with transport pathway distances to nearest surface water (estimated from topography, land cover and soil data) yield travel time distribution scenarios. Not all of these underlying control factors of advection variability are equally or similarly important in determining relevant travel time distribution scenarios in different catchments. The individual effects of different control factors may further have similar, overlapping effects on the resulting travel time distributions. For instance, fine-resolved variability in local topographic slopes can be translated into a scenario of high hydraulic gradient variability as done by Darracq et al. (2010a), yielding similarly large spreading of travel times as does the present scenario 2 with fine-resolved $K$ variability but coarser (subcatchment-wise) hydraulic gradient resolution.

Our results also demonstrate how geographic mapping of advective travel times to a sensitive recipient from all potential pollutant and nutrient input locations within a catchment can be used to identify hotspot areas with large potential mass loading to the recipient, and their opposite, areas with the potentially lowest loading within a catchment. Such substance-independent calculations and mapping of advective travel times can thus be useful for at least approximate predictive identification of the parts of a catchment area where pollutant and nutrient releases are most and least likely to contribute much to pollution or eutrophication of downstream water systems, and where environmental protection/remediation measures may be most and least needed and effective. Maps of advective travel times and mass delivery to a recipient from different parts of a catchment are also relevant for the assessment of the risk of pollution or eutrophication from multiple local sources and from diffuse sources that are spatially variable.
Acknowledgements. We thank the Swedish Research Council (VR; project number 2006-4366, contract number 60436601) for financial support of this work, which has also been carried out in and links the frameworks of Stockholm University's strategic environmental research programme EkoKlim and marine environmental research programme BEAM.

Edited by: B. Schaefli

\section{References}

Andricevic, R. and Cvetkovic, V.: Evaluation of risk from contaminants migrating by ground water, Water Resour. Res., 32, 611621, 1996

Aronson, D. and Howard, P. H.: Anaerobic biodegradation of organic chemicals in groundwater: A summary of field and laboratory studies, Syracuse Research Corporation, North Syracuse, NY, USA, 1997.

Aronson, D., Citra, M., Shuler, K., Printup, H., and Howard, P. H.: Aerobic biodegradation of organic chemicals in environmental media: A summary of field and laboratory studies, Syracuse Research Corporation, North Syracuse, NY, USA, 1999.

Baresel, C. and Destouni, G.: Uncertainty-accounting environmental policy and management of water systems, Environ. Sci. Technol., 41, 3653-3659, doi:10.1021/es061515e, 2007.

Baresel, C., Destouni, G., and Gren, I.-M.: The influence of metal source uncertainty on cost-effective allocation of mine water pollution abatement in catchments, J. Environ. Manage., 78, 138148, doi:10.1016/j.jenvman.2005.03.013, 2006.

Basu, N. B., Destouni, G., Jawitz, J. W., Thompson, S. E., Loukinova, N. V., Darracq, A., Zanardo, S., Yaeger, M. A., Sivapalan, M., Rinaldo, A., and Rao, P. S. C.: Nutrient loads exported from managed catchments reveal emergent biogeochemical stationarity. Geophys. Res. Lett., 37, L23404, doi:10.1029/2010GL045168, 2010.

Batchelor, B., Valdés, J., and Araganth, V.: Stochastic risk assessment of sites contaminated by hazardous waste, J. Environ. Eng., 124, 380-388, 1998.

Bayer-Raich, M., Jarsjö, J., Liedl, R., Ptak, T., and Teutsch, G.: Integral pumping test analyses of linearly sorbed groundwater contaminants using multiple wells: Inferring mass flows and natural attenuation rates, Water Resour. Res., 42, W08411, doi:10.1029/2005WR004244, 2006.

Bekins, B. A., Warren, E., and Godsy, E. M.: A comparison of zeroorder, first-order, and Monod biotransformation models, Ground Water, 36, 261-268, 1998.

Bergknut, M., Meijer, S., Halsall, C., Ågren, A., Laudon, H., Köhler, S., Jones, K. C., Tysklind, M., and Wiberg, K.: Modelling the fate of hydrophobic organic contaminants in a boreal forest catchment: A cross disciplinary approach to assessing diffuse pollution to surface waters, Environ. Pollut., 158, 29642969, 2010.

Beven, K. J.: A manifesto for the equifinality thesis, J. Hydrol., 320, 18-36, 2006.

Beven, K. J.: Preferential flow and travel time distributions: defining adequate hypothesis tests for hydrological models, Hydrol. Process., 24, 1537-1547, 2010.

Brydsten, L. and Strömgren, M.: Digital elevation models for site investigation programme in Forsmark. Swedish Nuclear Fuel and 
Waste Management Company Report P-04-70, Stockholm, 2004. Carpenter, S. R., Caraco, N. F., Correll, D. L., Howarth, R. W., Sharpley, A. N., and Smith, V. H.: Nonpoint pollution of surface waters with phosphorus and nitrogen. Ecol. Appl., 8, 559-568, 1998.

Chapell, F. H.: The significance of microbial processes in hydrology and geochemistry, Hydrogeol. J., 8, 41-46, 2000.

Cozzarelli, I. M., Herman, J. S., Baedecker, M. J., and Fischer, J. M.: Geochemical heterogeneity of a gasoline-contaminated aquifer, J. Contam. Hydrol., 40, 261-284, 1999.

Cunningham, J. A. and Fadel, Z. J.: Contaminant degradation in physically and chemically heterogeneous aquifers, J. Contam. Hydrol., 94, 293-304, 2007.

Cvetkovic, V. and Dagan, G.: Transport of kinetically sorbing solute by steady random velocity in heterogeneous porous formations, J, Fluid Mech., 265, 189-215, 1994.

Cvetkovic, V. and Shapiro, A.: Mass arrival of sorptive solute in heterogeneous porous media, Water Resour. Res., 26, 2057-2067, 1990.

Cvetkovic, V., Dagan, G., and Shapiro, A. M.: A solute flux approach to transport in heterogeneous formations 2: Uncertainty analysis, Water Resour. Res., 28, 1377-1388, doi:10.1029/91WR03085, 1992.

Darracq, A. and Destouni, G.: Physical versus biogeochemical interpretations of Nitrogen and Phosphorus attenuation in streams and its dependence on stream characteristics, Global Biogeochem. Cy., 21, GB3003, doi:10.1029/2006GB002901, 2007.

Darracq, A., Greffe, F., Hannerz, F., Destouni, G., and Cvetkovic, V.: Nutrient transport scenarios in a changing Stockholm and Mälaren valley region, Water Sci. Technol., 51, 31-38, 2005.

Darracq, A., Lindgren, G. A., and Destouni, G.: Long-term development of phosphorus and nitrogen loads through the subsurface and surface water systems of drainage basins, Global Biogeochem. Cy., 22, GB3022, doi:10.1029/2007GB003022, 2008.

Darracq, A., Destouni, G., Persson, K., Prieto, C., and Jarsjö, J.: Quantification of advective solute travel times and mass transport through hydrological catchments, Environ. Fluid Mech., 10, 103-120, doi:10.1007/s10652-009-9147-2, 2010a.

Darracq, A., Destouni, G., Persson, K., Prieto, C., and Jarsjö, J.: Scale and model resolution effects on the distributions of advective solute travel times in catchments, Hydrol. Process., 24, 1697-1710, doi:10.1002/hyp.7588, 2010b.

Destouni, G. and Cvetkovic, V.: Field scale mass arrival of sorptive solute into the groundwater, Water Resour. Res. 27, 1315-1325, 1991.

Destouni, G., Lindgren, G., and Gren, I. M.: Effects of inland nitrogen transport and attenuation modeling on coastal nitrogen load abatement, Environ. Sci. Technol., 40, 6208-6214, doi:10.1021/es060025j, 2006.

Destouni, G., Hannerz, F., Prieto, C., Jarsjö, J., and Shibuo, Y.: Small unmonitored near-coastal catchment areas yielding large mass loading to the sea, Global Biogeochem. Cy., 22, GB4003, doi:10.1029/2008GB003287, 2008.

Destouni, G., Persson, K., Prieto, C., and Jarsjö J.: General quantification of catchment-scale nutrient and pollutant transport through the subsurface to surface and coastal waters, Environ. Sci. Technol., 44, 2048-2055, 2010.

Edwards, A. C. and Withers, P. J. A.; Transport and delivery of suspended solids, nitrogen and phosphorus from various sources to freshwaters in the UK, J. Hydrol., 350, 144-153, 2008.

Eggleston, J. R. and Rojstaczer, S. A.: Can we predict subsurface mass transport?, Environ. Sci. Technol., 34, 4010-4017, 2000.

Essaid, H. I., Cozzarell, I. M., Eganhouse, R. P., Herkelrath, W. N., Bekins, B. A., and Delin, G. N.: Inverse modeling of BTEX dissolution and biodegradation at the Bemidji, $\mathrm{MN}$ crude-oil spill site, J. Contam. Hydrol., 67, 269-299, 2003.

Ganoulis, J.: Risk Analysis of Water Pollution: Second, revised and expanded edition, WILEY-VCH Verlag, Weinheim, 2009.

Gren, I. M., Destouni, G., and Sharin, H.: Cost effective management of stochastic coastal water pollution, Environ. Model. Assess., 5, 193-203, 2000.

Hagemann, S. and Jacob, D.: Gradient in the climate change signal of European discharge predicted by a multi-model ensemble, Climatic Change, 81, 309-327, 2007.

Hannerz, F. and Destouni, G.: Spatial characterization of the Baltic Sea Drainage Basin and its unmonitored catchments, Ambio, 35, 214-219, 2006.

Howden, N. J. K, Burt, T. P, Mathias, S. A., Worrall, F., and Whelan, M. J.: Modelling long-term diffuse nitrate pollution at the catchment-scale: Data, parameter and epistemic uncertainty, J. Hydrol., 403, 337-351, 2011.

Jacob, D., Bärring, L., Christensen, O. B., Christensen, J. H., Hagemann, S., Hirschi, M., Kjellström, E., Lenderink, G., Rockel, B., Schär, C., Seneviratne, S. I., Somot, S., van Ulden, A., and van den Hurk, B.: An inter-comparison of regional climate models for Europe: design of the experiments and model performance. Climatic Change 81(Supplement 1), 31-52, 2007.

Jardine, P. M.: Influence of coupled processes on contaminant fate and transport in subsurface environments, Adv. Agronomy, 99, doi:10.1016/S0065-2113(08)00401-X, 2008.

Jarsjö, J. and Bayer-Raich, M.: Estimating plume degradation rates in aquifers: effect of propagating measurement and methodological errors, Water Resour. Res., 44, W02501, doi:10.1029/2006WR005568, 2008.

Jarsjö, J., Bayer-Raich, M., and Ptak, T.: Monitoring groundwater contamination and delineating source zones at industrial sites: Uncertainty analyses using integral pumping tests, J. Contam. Hydrol., 79, 107-134, 2005.

Jarsjö, J., Shibuo, Y., and Destouni, G.: Spatial distribution of unmonitored inland water flows to the sea, J. Hydrol., 348, 59-72, 2008.

Johansson, P.-O.: Description of surface hydrology and nearsurface hydrogeology at Forsmark, Site descriptive modelling, SDM-Site Forsmark. Swedish Nuclear Fuel and Waste Management Co Report R-08-08, 2008.

Johansson, P.-O. and Öhman, J.: Presentation of meteorological, hydrological and hydrogeological monitoring data from Forsmark: Site descriptive modelling - SDM-Site Forsmark, Swedish Nuclear Fuel and Waste Management Co Report R-08-10, 2008.

Johansson, P.-O., Werner, K., Bosson, E., and Juston, J.: Description of climate, surface hydrology, and near-surface hydrology. Preliminary site description. Forsmark area - version 1.2. Swedish Nuclear Fuel and Waste Management Co Report R-0506, 2005.

Kyselý, J. and Beranová, R.: Climate change effects on extreme precipitation in central Europe: uncertainties of scenarios based on regional climate models, Theor. Appl. Climatol., 95, 361-374, 
2009.

Lindgren, G. A. and Destouni, G.: Nitrogen loss rates in streams: Scale-dependence and up-scaling methodology, Geophys. Res. Lett., 31, L13501, doi:10.1029/2004GL019996, 2004.

Malmström, M. E., Destouni, G., and Martinet, P.: Modeling expected solute concentration in randomly heterogeneous flow systems with multicomponent reactions, Environ. Sci. Technol., 38, 2673-2679, 2004.

Malmström, M. E., Berglund, S., and Jarsjö, J.: Combined effects of spatially variable flow and mineralogy on the attenuation of acid mine drainage in groundwater, Appl. Geochem. 23, 1419-1436, doi:10.1016/j.apgeochem.2007.12.029, 2008.

McDonnell, J. J., McGuire, K., Aggarwal, P., Beven, K., Biondi, D., Destouni, G., Dunn, S., James, A., Kirchner, J., Kraft, S., Lyon, S., Malowszewski, P., Newman, L., Pfister, L., Rinaldo, A., Rodhe, A., Sayama, T., Seibert, J., Soloman, K., Soulsby, C., Stewart, M., Tetzlaff, D., Tobin, C., Troch, P., Weiler, M., Western, A., Wörmann, A., and Wrede, S.: How old is stream water? Open questions in catchment transit time conceptualisation, modelling and analysis, Hydrol. Process., 24, 1745-1754, 2010.

McGuire, K. J., McDonnell, J. J., Weiler, M., Kendall, C., McGlynn, B. L., Welker, J. M., and Seibert, J.: The role of topography on catchment-scale water residence time, Water Resour. Res. 41, W05002.1-W05002.14, doi:10.1029/2004WR003657, 2005.

Mulligan, C. N. and Yong, R. N.: Natural attenuation of contaminated soils, Environ. Int., 30, 587-601, 2004.
Persson, K. and Destouni, G.: Propagation of water pollution uncertainty and risk from the subsurface to the surface water system of a catchment, J. Hydrol., 377, 434-444, doi:10.1016/j.hydrol.2009.09.001, 2009.

Rogers, S. W., Ong, S. K., Kjartanson, B. H., Golchin, J., and Stenback, G. A.: Natural attenuation of polycyclic aromatic hydrocarbon-contaminated sites: review. Pract. Periodical Haz., Toxic, and Radioactive Waste Mgmt., 6, 141-155, 2002.

Refsgaard, J. C., van der Sluijs, J. P., Brown, J., and van der Keur, P.: A framework for dealing with uncertainty due to model structure error, Adv. Water Resour., 29, 1586-1597, 2006.

Sinkkonen, S. and Paasivirta, J.: Degradation half-life times of PCDDs, PCDFs and PCBs for environmental fate modeling, Chemosphere, 40, 943-949, 2000.

SKB: Site description of Forsmark at completion of the site investigation phase: SDM-Site Forsmark. Swedish Nuclear Fuel and Waste Management Co Report TR-08-05, 2008.

Suarez, M. P. and Rifai, H. S.: Biodegradation rates for fuel hydrocarbons and chlorinated solvents in groundwater, Bioremediation Journal, 3, 337-362, 1999.

Washington, J. W. and Cameron, B. A.: Evaluating degradation rates of chlorinated organics in groundwater using analytical models, Environ. Toxicol. Chem., 20, 1909-1915, 2001.

Werner, K., Johansson, P., Brydsten, L., Bosson, E., Berglund, S., Tröjbom, M., and Nyman, H.: Recharge and discharge of nearsurface hydrology, Swedish Nuclear Fuel and Waste Management Co Report R-07-08, 2007. 